\title{
On National Fitness and Training of Social Sports Professionals
}

\author{
Li Zhang and Yijian Deng \\ NanChang Institute of Science and Technology, Nanchang, 330108
}

\author{
Keywords: National fitness; Social sports professionals; Training of talents; National fitness
}

\begin{abstract}
With the rapid economic and social development of China and the gradual improvement of people's living standards, physical fitness activities have become more and more common and people have also incorporated physical exercises into their routine daily life. As a mass sports activity, national fitness exercise plays a significant social role with great importance in the comprehensive prevention of "civilized diseases" in the context of contemporary society. Aiming at that national fitness needs social sports professionals with abundant practical abilities and social sports professionals need the platform of national fitness, this paper integrates national fitness and the training of social sports professionals so as to improve the system of training social sports professionals and meet the need of national fitness. In response to the current situation of the demand for national fitness and the problems existing in the training of social sports professionals, the paper puts forward the integrated measures and suggestions for the national fitness training and social sports professionals training.
\end{abstract}

\section{Introduction}

With the prevalence of national fitness exercise, the quality and quantity of social sports professionals cannot meet people's demands more and more. The status quo and existing problems become more and more prominent. This also shows that although universal fitness exercise is the focus of current work, how to carry out national fitness exercise is a difficult task as well as how to correctly guide the masses to actively, voluntarily and effectively participate in the fitness exercise. Meanwhile, there should also be rules to follow in exercise to avoid blindly exercising and it is an urgent issue to form national fitness and lifelong sports training. At present, the sources of training social sports professionals mainly include two aspects: colleges at various sports colleges and various social sports instructors. The two complement each other and jointly assume the tasks of national fitness. And instructors who can guide the mass to take exercise as social sports are the focus of training at colleges and universities.

\section{Current Situation of Cultivating Social Sports Professionals}

Imbalance between Training Objectives and Social Needs. The new type of national fitness service personal should theoretically include the national fitness talents with national fitness managers, social sports instructors, national sports volunteers, retired sportsmen, social and sports organization leaders, fitness models and media experts as the core. At present, there are 230 institutions of higher learning that set social sports instruction and management major across the country, covering all provinces, municipalities and autonomous regions. However, the training objectives are mostly concentrated in the field of fitness counseling, technical guidance and organization and management. The physical education major has not set up a talent cultivation course in the curriculum, and there is no practice link for the cultivation of the national fitness service personnel. There are still many gaps in the cultivation of students' social adaptability, professional skills, fitness knowledge reserve and social needs.

Disjunction between Teaching Activities and Social Needs. Classroom teaching is the main way to train qualified talents. With the promulgation of the "Outline", it can be clearly seen that the contradiction between the people's increasingly diversifies and multi-layered sports needs and the effective supply of sports is still outstanding. The concrete manifestation is that the social forces involved in nationwide fitness are not mobilized enough, the development of sports social 
organizations at all levels is relatively slow, the quantity is too small, and the role played is not enough. Inadequate provision of effective sports is mainly manifested in the school's training objectives did not keep up with the actual needs of the market, including the lack of local characteristics of curriculum content, obsolete professional knowledge, and the actual needs of the community seriously out of line.

Most of the teaching content only focuses on the main courses: exercise physiology, human anatomy, sports psychology, track and field, martial arts, gymnastics, ball games and so on. Teaching and practice are all around the sports at school with less involving social and sports knowledge, ability and health concepts and insufficient national fitness knowledge. Therefore, we should do a good job in classroom teaching and standardize the training of the nationwide fitness service personnel as a regular in the classroom, so as to foster the normalization of students' awareness of nationwide fitness services and create a good atmosphere for learning so as to keep up with the pace of social development.

\section{An Analysis of Existing Problems and Causes of Social Sports Professionals Training}

The quantity and quality of social sports professionals cannot meet people's needs more and more and the problems in their cultivation become more and more prominent. At present, the sources of social sports professionals mainly include two aspects: college students in sports colleges and various social sports instructor. The two complement each other and share the tasks of the national fitness exercise. Taking into account their different nature and origin, the existing problems must be analyzed separately. It has not been a long time since colleges and universities start the social sports major and the training objectives are not clear, so students have limited employment after graduation, which also reveals that the training objectives are not targeted. Under the influence of physical education major, some teaching of social sports major seriously neglects the teaching of technology, which leads to the fact that although students have perfect technical skills, and they have no solution to the guidance of social education.

The schools are inaccurate in positioning their cultivation targets and are out of touch with the needs of the society. They are seriously lacking in pertinence and thus cannot be linked to the current fitness programs such as the Health Qigong and Tai Chi among popular martial arts programs, combining with the actual needs of the masses Teaching, training students. The content of professional courses still needs further deepening of reform. Some courses are outdated and out of practice. They have obviously failed to keep up with the development of economy, society and science and technology, and lack of information, making it difficult to meet students' learning needs. In addition, the overall teacher strength is not high, the structure is irrational, etc., eventually leading to students' lack of independent ability to guide the social sports after graduation, being eliminated in the talent competition, resulting in waste of educational resources.

\section{Research and Suggestion on Integrating National Fitness and Social Sports Professionals Training}

The development of national fitness exercise and fitness service system are inseparable from the social sports professionals. The more professional the social sports instructor, the stronger the professionalism of the entire national fitness team, and the more appropriate the service will be. And the system will become more and more perfect. Colleges and universities should manage the social sports talents effectively, avoid the loss of talents, try their best to organize and carry out the national fitness exercise to meet the needs of people's life, achieve social stability and promote the vigorous development of China's sports industry.

Reconstruction of Professionals Cultivation Mode. Social sports practice teaching and experiment go hand in hand to be strengthened. Practice and experimental teaching, as the key link in the process of professional PE teaching and scientific research, are crucial in the acquisition and verification of knowledge and ability cultivation. The practice training is based on practical teaching base, and its development and construction are directly associated with students' 
theoretical knowledge and the ability to combine practice. Meanwhile, in order to achieve good effect in practical teaching, it is necessary to grasp six links and one system and principle, i.e., experiment, training, internship, skill training, social practice and extracurricular activities, teaching qualification certificate, athlete skill certificate, judge certificate, diploma and degree certificate.

Creation and Compilation of Professional and Authoritative Textbooks. In view of the current national fitness background, numerous martial arts enthusiasts emerge, and martial arts has a more extensive mass base, and is popular in the national fitness movement, so it is necessary to create a martial arts project authoritative social guidance materials. A system of standardized professional martial arts instructional materials is not only conducive to learning and assessment of social instructors justified, and enhance the guidance of the professional and scientific. And this helps a large number of martial arts enthusiasts to learn skill and teaching methods under the blueprint, avoid the blindness of exercise, and as a model and guideline, and it is conducive to the inheritance of martial arts culture.

Emphasis on Both the Technical Training and Knowledge of Social Instructors. At this stage, social sports instructors professionalism varies greatly, seemingly growing team. However, in actual work, there are only a few people who can hold the top spot. Therefore, in the training of instructors, its professional knowledge and professional skills should be strengthened, focusing on the cultivation and training of teaching methods. Take Tai Chi in martial arts as an example, the main points of the basic movements can be summed up in time to summarize and correct, such as the body to be Chiang Kai-shek, the action should be endless, on the square, the park in the cat's waist, jerky and other actions are not standardized common mistakes can be corrected. This also reflects that social sports instructors should try to correct and regulate the key points of amateur sports lovers' wrong actions, which is an important link of carrying out communication work that can help to lead them get out of the erroneous zone fundamentally and establish correct concept of fitness and sports.

\section{Conclusion}

The development of China's sports undertakings should go to the deep integration of mass sports and competitive sports. Throughout the development of national fitness exercise in our country, based on the perspective of healthy construction and school sports development in our country, we should integrate the relationship between teaching and training and social services, increase the promotion of national fitness programs and the training of service personnel, pay attention to the forms of fitness for all, diversify the exercise content, exercise methods, and specialization of service contents and service means to better meet the different needs of different fitness groups, different levels and objects, regions, occupations, and ages so as to adapt to the "national health" pattern.

\section{References}

[1] Zhang Y P, Yang L Q, Zhi-Fang R, et al. The Necessity to Set Up the Course of National Fitness Dance in Social Sports Specialty[J]. Journal of Lanzhou University of Arts \& Science, 2014.

[2] Huang W. Thoughts on Developing Community and Promoting National Fitness Sports[J]. Fujian Sports Science \& Technology, 2001.

[3] Polli G M, Wachelke J. Research on the Present Situations of the National Fitness Sports in the Areas of the Three Rivers[J]. Journal of Qinghai Normal University, 2013, 21(1):97-104.

[4] Zhou C Z, Ai-Min Z, Yang R. Construction of family sports and national fitness program system[J]. Journal of Wuhan Institute of Physical Education, 2005.

[5] Shanxu Y U. A Discussion on the System Promotion of Regulations on National Fitness to Public Sports Service[J]. Journal of Tianjin University of Sport, 2010.

[6] Pan J Q, Wei L C. Role Definition of Ethnic Traditional Sports under National Fitness Program[J]. Journal of Hebei Institute of Physical Education, 2010. 
[7] Dong Q. On the Western Region National Fitness and the Development of Traditional Sports of Minority Nationalities[J]. Journal of Gansu Lianhe University, 2009.

[8] Tan T C, Hong F. The Transformation of China's National Fitness Policy: From a Major Sports Country to a World Sports Power[J]. International Journal of the History of Sport, 2015, 32(8):1071-1084.

[9] Jiang X M. Discussion on National Fitness Sports Pattern in Minority Region[J]. Bulletin of Sport Science \& Technology, 2014.

[10] Yang X D. The Integration of Regional Folk Sports and National Fitness in the View of Healthy China[J]. Journal of Yanan University, 2017.

[11] Wang M, University C S. On the Importance of the Reform of School Sports Competition from the Perspective of "National Fitness"[J]. Contemporary Sports Technology, 2017.

[12]Wang S F. Study on the Sustainable Development of Rural Sports Associations in the Perspective of National Fitness[J]. Fujian Sports Science \& Technology, 2016. 